\begin{tabular}{ccc}
\hline & International Journal of Engineering \& Technology, 7 (2.29) (2018) 20-23 \\
SPC & International Journal of Engineering \& Technology \\
\hline
\end{tabular}

\title{
Development of high frequency generator for bipolar electrosurgical unit
}

\author{
Ali Idham alzaidi*1, Azli yahya ${ }^{2}$, Tan Tian Swee', Norhalimah Idris ${ }^{3}$ \\ ${ }^{1}$ Faculty of Biomedical Engineering, Universiti Teknologi Malaysia, 81310 Skudai Johor, Malaysia \\ ${ }^{2}$ Faculty of Electrical Engineering, Universiti Teknologi Malaysia, 81310 Skudai Johor, Malaysia \\ ${ }^{3}$ Faculty of Management, Universiti Teknologi Malaysia, 81310 Skudai Johor, Malaysia \\ *Corresponding author E-mail: alii.alzedi@gmail
}

\begin{abstract}
Power Electronics is widely used in bioscience and medical instruments such as Electrosurgical Units, MRI and X-ray. An advance development in switch mode power supply leads to a new design topology of DC to DC convertor for Electrosurgical Systems. The new designed system has a capacity to produce high efficient output power with high resonance, this improves the performance of the surgery operation. This paper reports a Buck-Boost topology DC to DC (Flyback) converter with high power switching. The simulation results show an improved performance when compared to the existing system.
\end{abstract}

Keywords: SMPS; DC to DC Converter; Electrosurgical Unit;

\section{Introduction}

Electrosurgery cuts cells by emitting energy into the human body tissue and quickly boiling the waters in the cells, causing them to burst. This Technology has been used for approximately 80 years, and the current and voltage performance has been developed and enhanced by solid state generators, revolutionizing Electrosurgery generators [1]. To prevent muscle stimulation, the output of the generators will be high frequency AC waveforms at more than $200 \mathrm{kHz}$ [4]. The power required for these surgeries, can start from tens to hundreds of the watts on an arc modelled as a load between hundreds of Ohms to thousands of Ohms [2]. When compared to other high frequency surgery methods such as laser surgery, Electrosurgical Generators (ESG) have lower levels of collateral cell damage. All the ESG processes can be controlled with high accuracy by using the small and highly efficient power electronic element [3].

This paper proposes a Flyback converter power supply with single phase inverter topology taking advantage of IGBT devices [9] in order to improve performance and a high power density implementation. The proposed converter enables to generate useful waveforms required by the application with the advantage of controlling the voltage depending on the requirements[4].The block diagram in Figure 1 shows the DC power supply connected to flyback converter which lead to produce the dc required for main inverter from DC to AC voltage which applied to step up transformer to get the voltage required.

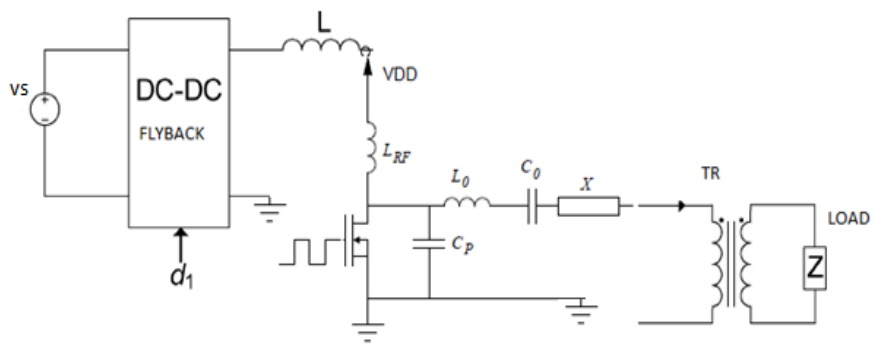

Fig. 1: Block diagram of flyback with inverter

\section{Electrosurgical Power Supply DC to DC Converter}

Electrosurgical units consist of four components, which are: power supply, radio frequency generator, active electrode and return electrode. The electrosurgical generator controls the energy required and the frequency value which has the SMPS DC to DC converter. This main task of the converter is to produce the electrical signal with highly accurate uniform electrical discharge in the form of AC current. It also controls the amount of heat supply to electrode. In conventional ESU, power level and frequency are high, thus, the electrode will burn and char the tissue [5]. Also, the power sources developed go from ' full wave rectifier to the complex resonant power supply unit. The electro surgery generator is the active part of ESU system and responsible for achieving the required values with very high accuracy. The first generator for ESU is able to produce an unstable signal as pulses. However, these pulses pass through the electrode without any control on the output. The new design of ESG uses the Controller to control the output wave generation, which will overcome the drawback of the commercial ESG [6]. The input voltage is corrected and the DC voltage is applied to the DC-DC convertor. During this study, flyback SMPS are going to be selected for the development of the new ESG for ESU system 
[1]. This is the result of the output power levels (150 Watts), as the planning for the electrical device is comparatively straightforward. Additionally, just one magnetic component (flyback transformer) is employed as no inductors is utilized in the output filter. Multiple outputs may be obtained, by employing a minimum range of components, as conjointly, they have a wide input voltage [7].

\section{Design and Development}

The end goal is to produce a power source competent enough to create the voltage and frequencies required for users. To achieve this goal, a few topologies can be utilized such as boost converters, inverters and so on., together with secondary circuits [3]. To create voltage wave, voltage beats are utilized ordinarily. However, a different sort of waves can also be utilized. The square wave is generally favoured due to the fact that it is less demanding to produce and control their parameters, such as recurrence and sufficiency [7, 8]. There are five different stages in the electrosurgical generator as illustrated in Figure 2. In our research we will focus on the converter DC-DC voltage and Radio frequency amplification. In the block diagram show below the sequence of the signal start with AC voltage input and end with $\mathrm{AC}$ voltage wave with high power and frequency[6]:

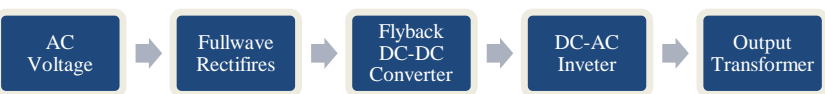

Fig. 2: The block diagram of new model ESG

The aim is to build a 50W radio frequency generator (RFG), which is suitable operation for electro surgery with Load (resistive 100 $\mathrm{ohm}$ ) while also reducing form factor from conservation of valuable operating room space. The estimated efficiency of the DC-DC converter is expected to be $90 \%$. And the Radio Frequency Amplifier (Resonant Amplifier) high efficiency is estimated to have a 92\% performance. Finally, the Output Transformer for amplification and isolation is estimated to reach a $91 \%$ efficiency.

\subsection{Flyback Converter}

Reversal of voltage polarities in secondary winding makes the diode forward biased, thus, it offers current to the capacitor and load. When Transistor Q is turned off, the primary side inductance produces back electromotive voltage and opposes current change [9] The load current is offered by the capacitor storage energy at previous switching period. When Q switched on, current flows in the primary, and energy is stored in the transformer inductance [1].As seen in Figure 4 the current direction in both case when $\mathrm{O} O N$ and OFF.
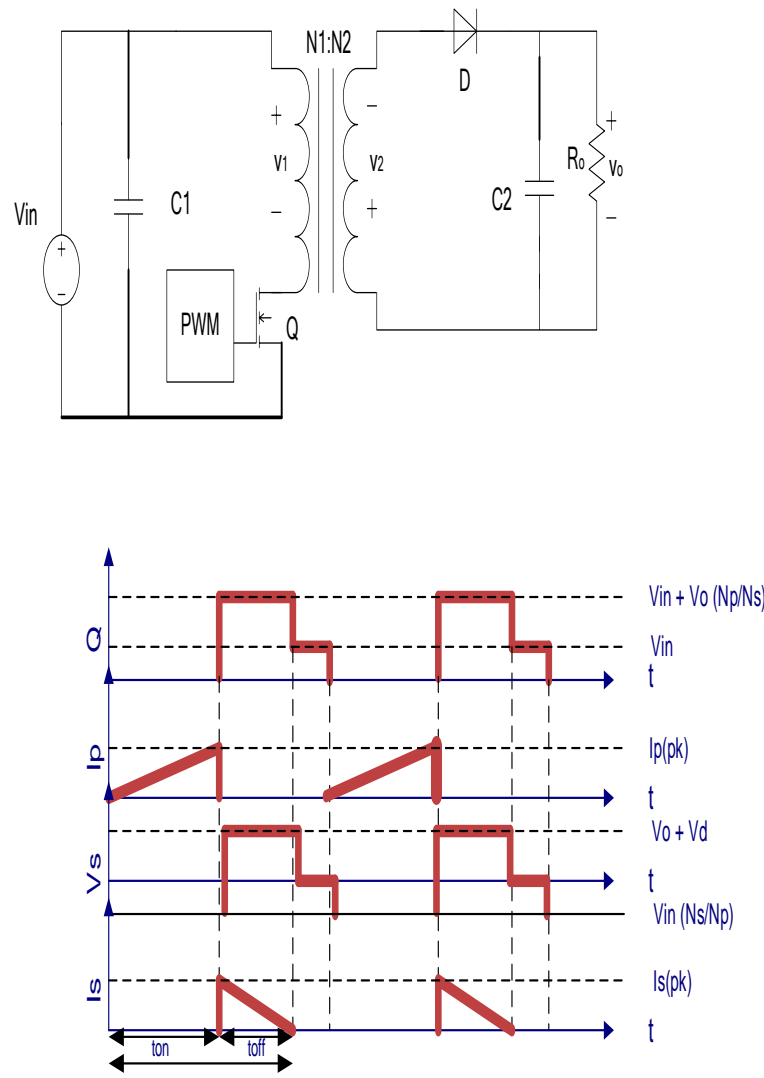

Fig. 4: Flyback SMPS equivalent circuit and Discontinuous current, flyback converter

In the discontinuous mode, the circuit topology results in a smaller inductor but put larger stress on the capacitor and switching device as shown in Figure 5 [7].

\subsection{Single phase inverter DC to AC}

These classes of amplifiers are true RF amplifiers or Power amplifier (PA) and are designed for a limited frequency range with small variations in load impedance [5]. The range of load impedance makes these topologies suitable for this application [10]. The PA schematic can be show in Figure 7. the inductor RFC work lone for example a DC basis (RF Choke, higher efficiency can be reached. To get a sinusoidal voltage from dc input at the output, low pass filter will have connected in the output of PA the frequency will control through the gate of power transistor.

\section{Results and Discussion}

The circuit design of SMPS is first described at section 3 and the behaviour model of the system is implemented using the SIMULINK in MATLAB. Simulink models are block diagram consisting of sources, sinks and various functional blocks for modelling a system. The overall system describes the SMPS condition when the switch is on and off. pulse generator is one of the most significant factors when mention a PWM method. This PWM signal can be produced simply by comparing a reference signal, $r(t)$, with a carrier signal (saw tooth carrier), $c(t)[11]$ as depicted in Figure 7 below [3].

While the output voltage, $v_{o}$ for switch on and off is the same.

$v_{o}=i_{c} r_{c}+v_{c}$

$v_{o}=\left(\frac{n_{1}}{n_{2}} i_{L}-i_{\text {out }}\right) r_{c}+v_{c}$ 


\subsection{Output control circuit DC to DC Converter}

The proposed model can be proven by designing and building a Flyback converter simulation. The nominal output power is $50 \mathrm{~W}$ and the switching frequency has been selected to be $1 \mathrm{MHz}$ to obtain the benefits of high frequency cutting [12]. The input voltage is $100 \mathrm{~V} \mathrm{dc}$ and the transformer has been designed to have a 1:1 turns ratio to obtain the desired output voltage while ensuring safe device operation. The capacitance in secondary is $68 \mathrm{mf}$ and resistance 100 $\mathrm{ohm}$. By considering all the behaviour when Switch Q is on and off, flyback SMPS model is created. The subsystem can be divided into inputs include $\left(v_{g}\right)$ and outputs part include $\left(v_{o}\right)$ [9]. From the output voltage graph obtained in the simulated model illustrated in Figure 7 it can be observed that by using PWM as switching module, the system is able to obtain up to $80 \mathrm{~V}$ output voltages and show the main waveform output voltage, which is control by PWM to get the required signal [13].

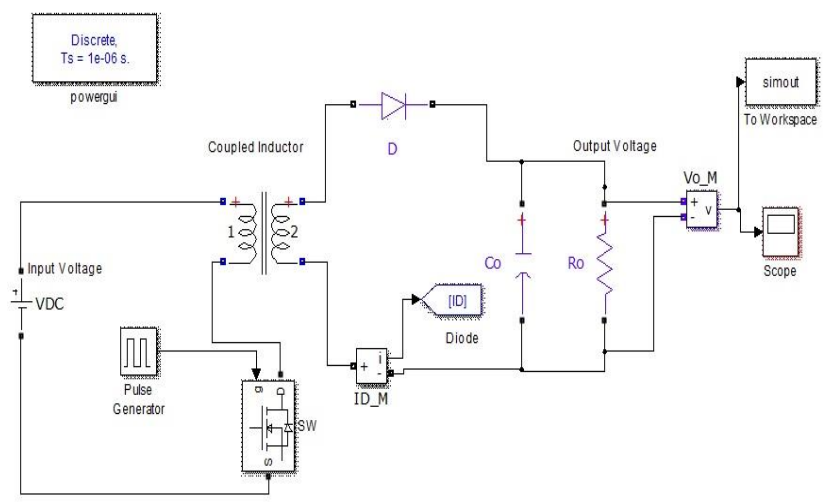

Fig. 7: Flyback converter Simulation

Main waveforms of the converter are shown in Figure 8. The output voltage is equivalent to the DC to DC flyback converter with a stable value and a high performance. By ensuring an elevated current, the ripple converter will be reduced, leading to reduced requirements in terms of $\mathrm{dv} / \mathrm{dt}$ for the gating signals. Main detailed signals obtained from a simulink simulation are illustrated in Figure 8.

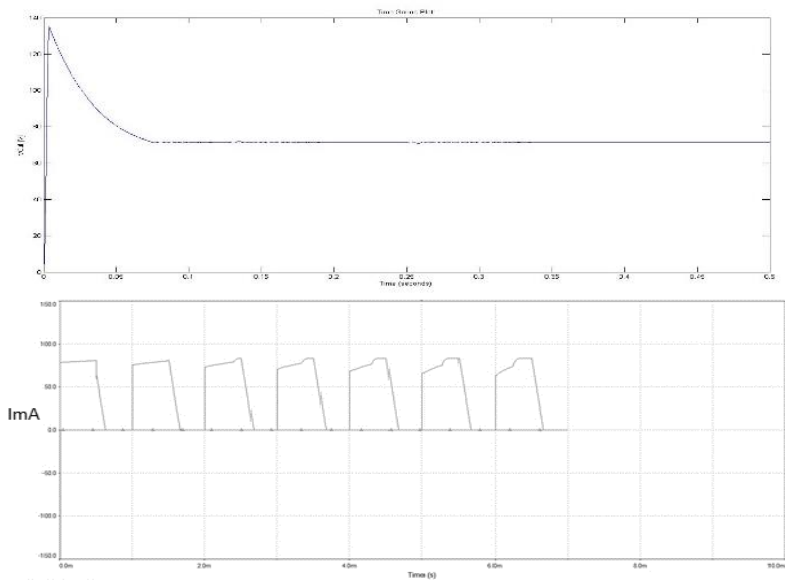

Figure 8: Flyback converter output waveforms voltage and current

\subsection{Generate AC Single by Phase Inverter}

The Power transistor MOSFETs selected to achieve a high frequency high power density implementation. These devices provide excellent performance at $1 \mathrm{MHz}$ while blocking up to $100 \mathrm{v}$ enabling a reliable and high performance implementation [14].

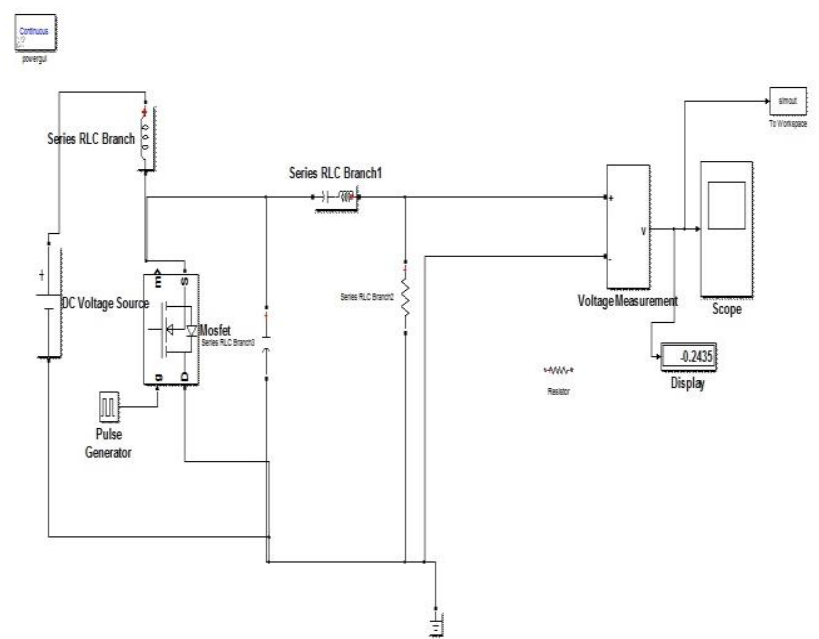

Fig. 9: Single phase power amplifier inveter

Figure 9 shows the main waveforms for cut modes. Unlike state-ofthe-art converters [15], the proposed approach enables the generator to attain any combination of output voltage and activation times, opening the design space to new optimum patterns to obtain the best cutting and coagulation performance [10].

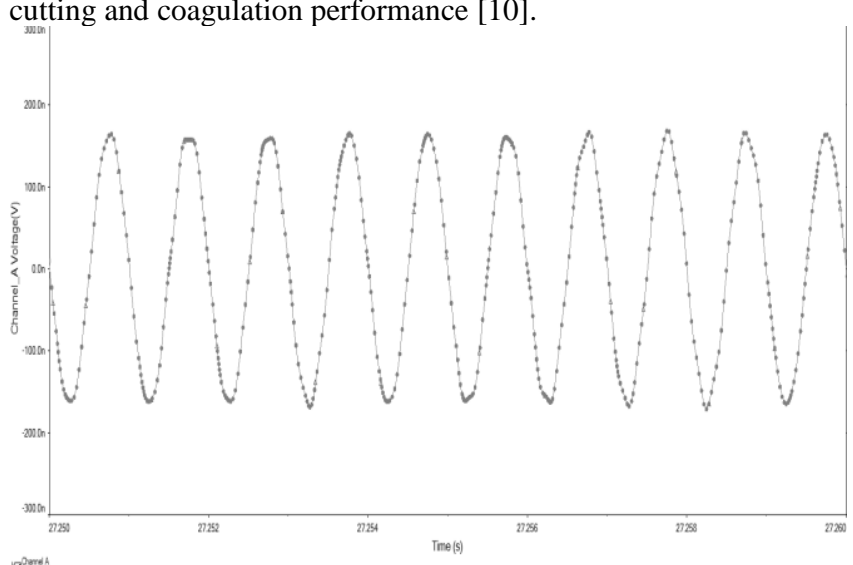

Fig. 9: Output voltage graph for dc to Ac

\section{Conclusion}

In this research, an Electrosurgical Generator Converter was developed with the specification of $1 \mathrm{MHz}$ as the output frequency. To verify the proposed model, a simulation in MATLAB was used alongside the SIMULINK add-on. The results of the simulated experiment show that the design is able to meet the desired design targets while at the same time maintain a high level of efficiency. The next step in the research is to design and develop a new generator for RFG and ESU power supply in which the efficiency of both DC to DC and RF stages are improved. The simulation of the converter will be implemented and built using actual hardware. The performance of the generator and the converter is expected to be improved by the implementation of circuits as well as the usage of switching modules. The developed ESG will be used for experimental analysis by machining. The experimental procedure will also be performed in order to identify the RF stage pattern for higher survival rate of ESG.

\section{References}

[1] Garcia-Garcia, J., et al., AC bipolar pulsed power supply for reactive magnetron sputtering. IEEE Transactions on Plasma Science, 2011. 39(10): p. 1983-1989.

[2] Grzesik, B. and M. Stepien. Power electronics in biomedical applications-An overview. in Power Electronics and Motion Control Conference (EPE/PEMC), 2012 15th International. 2012. IEEE. 
[3] Her, J., T. Wysoki, and B. Wysoki, Review of distributed beamforming. Journal of Telecommunications and Information Technology, 2011: p. 78-88.

[4] Sun, J., Pulse-width modulation, in Dynamics and Control of Switched Electronic Systems. 2012, Springer. p. 25-61.

[5] Nazriah, M., et al. Modeling of Flyback Converter for Micro Machining Biomedical Component. in Applied Mechanics and Materials. 2013. Trans Tech Publ.

[6] Alzaidi, A., et al., Wireless Bipolar Electrosurgical Device by Using Power Energy Transfer.

[7] Maniktala, S., Switching power supply design \& optimization. 2004: McGraw-Hill, Inc.

[8] Jensen, S., et al. Fast tracking electrosurgical generator using GaN switches. in Applied Power Electronics Conference and Exposition (APEC), 2015 IEEE. 2015. IEEE.

[9] Mudumbai, R., et al., Distributed transmit beamforming: challenges and recent progress. IEEE Communications Magazine, 2009. 47(2): p. 102-110.

[10] Sarnago, H., et al., A Versatile Multilevel Converter Platform for Cancer Treatment Using Irreversible Electroporation. IEEE Journal of Emerging and Selected Topics in Power Electronics, 2016. 4(1): p. 236-242.

[11] J. Sun, Pulse-Width Modulation, in Dynamics and Control of Switched Electronic Systems. 2012.

[12] Meng, X. and W. Cao, New Method to Detect Insulation On LineUltraviolet Image Method [J]. High Voltage Engineering, 2006. 6(32): p. 42-44.

[13] Sánchez-Trujillo, Á.-B., et al. Prototype of a plasma generator for electrosurgery. in Power Electronics (CIEP), 2016 13th International Conference on. 2016. IEEE.

[14] Sarnago, H., O. Lucia, and J. Burdío. High performance boost inverter featuring GaN-based devices for electro surgical units. in Applied Power Electronics Conference and Exposition (APEC), 2017 IEEE. 2017. IEEE.

[15] Stalder, K.R., D.F. McMillen, and J. Woloszko, Electrosurgical plasmas. Journal of Physics D: Applied Physics, 2005. 38(11): p. 1728. 